\title{
ACTIVIDADES DE LA ELIMINACIÓN DEL SARAMPIÓN EN LAS AMÉRICAS
}

\author{
Ciro A. de Quadros.
}

Director Special Program for Vaccines and Immunization. Organización Panamericana de la Salud.

\section{INTRODUCCIÓN}

En 1994, los países de las Américas establecieron el objetivo de eliminar el sarampión de la Región para el año $2000^{1}$.

El sarampión es una de las enfermedades más infecciosas. Antes que se descubriera la vacuna, casi todas las pcrsonas, a la larga, contraían el sarampión, generalmente en la infancia. Los seres humanos son el único reservorio del sarampión, aunque otros primates, como los monos, también pueden tener la infección. La fase más infecciosa es la prodrómica, antes de la aparición de síntomas tales como fiebre y exantema. La transmisibilidad disminuye rápidamente tras la aparición de exantema ${ }^{2}$.

A finales de los años setenta ya se había difundido la vacuna antisarampionosa de virus vivo atenuado, cuyo uso se autorizó en Estados Unidos en 1963․ Se ha comprobado que esta vacuna protege durante más de 20 años, y se cree que la inmunidad conferida por la dura toda la vida ${ }^{4}$. Esta vacuna tiene una eficacia del 90\% al 95\%. Debido a la interferencia de los anticuerpos maternos, la eficacia de la vacuna aumenta constantemente después de los 6 meses de vida, alcanzando el nivel máximo del $95 \%$ al $98 \%$ entre los 12 y los 15 meses de edad. Para 1982, prácticamente todos los países del mundo habian incorporado la vacuna antisarampionosa en sus planes de vacunación de rutina y, desde entonces, la cobertura ha aumentado considerablemente. En 1990, la co- bertura mundial de los niños de 2 años era del $70 \%$, aproximadamente.

Antes de la introducción de la vacuna contra el sarampión solía haber epidemias cada dos o tres años, en la mayoría de las zonas muy pobladas, pero con el uso generalizado de la vacuna se ha prolongado el intervalo entre epidemias ${ }^{5.6}$ y se ha observado un aumento en la edad promedio de las personas que contraen la infección.

En las Américas, los casos notificados han disminuido notablemente y la mayoría de los países han notificado una reducción del $99 \%$ en la incidencia, en comparación con la época anterior a la vacuna.

En los países en desarrollo que introdujeron la vacuna recientemente, en los que todavía no se ha alcanzado una cobertura de vacunación elevada, el sarampión sigue siendo endémico. La mayoría de los casos se producen en niños pequeños y lactantes ${ }^{7}$. La Organización Mundial de la Salud (OMS) calcula que todavía se producen anualmente 40 millones de casos de sarampión y un millón de muertes.

\section{La estrategia de la OPS para erradicar el sarampión}

La OPS recomienda una estrategia que procura interrumpir rápidamente la transmisión del sarampión, por medio de una campaña de vacunación masiva inicial (campaña de puesta al día), dirigida a todos los niños 
de 9 meses a 14 años. La transmisión se mantiene interrumpida con un alto grado de inmunidad de la población, mediante la vacunación de los lactantes en los servicios de vacunación de rutina. Estas medidas se complementan con campañas periódicas de vacunación masiva cada cuatro años (campañas de seguimiento), dirigidas a todos los niños de 1 a 4 años, aunque ya estén vacunados. La vigilancia de las enfermedades febriles y exantemáticas, así como del virus del sarampión, son otros componentes decisivos de la estrategia ${ }^{8}$.

La campaña inicial de puesta al día con la vacunación contra el sarampión se realiza en períodos de baja transmisión. Todos los niños de 9 meses a 14 años, aunque ya estén vacunados o hayan tenido sarampión, reciben la vacuna en un período muy corto, generalmente de una semana a un mes. Estas campañas conducen a un rápido aumento de la inmunidad en la población y, si se alcanza una cobertura suficientemente alta, se interrumpe la transmisión del sarampión.

Después de una campaña de puesta al día podrían quedar focos de niños susceptibles. Para detectarlos se realiza una evaluación después de la campaña de puesta al día, y en los lugares donde queden focos se deben organizar actividades especiales de vacunación (operaciones de barrido) a fin de aumentar la cobertura.

Tras la campaña inicial de puesta al día y las operaciones de barrido, los servicios de vacunación de rutina (vacunación de mantenimiento) deben velar para que todas las cohortes de niños nacidos el mismo año reciban una dosis de vacuna antisarampionosa entre los 12 y los 15 meses de edad.

Sin embargo, con el tiempo, inevitablemente, se irán acumulando preescolares susceptibles. Dos factores importantes contribuyen a esta acumulación. Primero, la vacuna antisarampionosa no es $100 \%$ eficaz, de modo que algunos niños no están protegidos a pesar de estar vacunados. Segundo, la co- bertura de vacunación contra el sarampión, de cada cohorte de niños nacidos el mismo año, no llegará nunca al $100 \%$, por más eficaz que sea el programa.

Por consiguiente, la estrategia actual incluye campañas de vacunación periódicas de preescolares, que se recomiendan cada vez que la cantidad de preescolares susceptibles (menores de 5 años) se acerque al tamaño de una cohorte promedio de niños nacidos el mismo año. En las Américas se recomienda realizar estas campañas de seguimiento cada cuatro años.

Un programa de vigilancia sensible es indispensable para el programa de eliminación del sarampión. Abarca la notificación y la investigación oportuna de lactantes y niños que se sospeche que tienen sarampión. Para confirmar o descartar la infección en los casos sospechosos se realizan pruebas serológicas, a fin de detectar anticuerpos IgM contra el sarampión. Un caso confirmado debe tener confirmación serológica o un vínculo epidemiológico con otro caso confirmado en laboratorio. La determinación de la secuencia del genoma del virus del sarampión a partir de aislamientos, procedimiento que se realiza en un laboratorio, puede facilitar la determinación de las fuentes geográficas de los brotes y los trayectos de transmisión.

Desde 1991, todos los paises de la OPS, excepto Estados Unidos, han realizado campañas de puesta al día con la vacunación contra el sarampión (tabla 1) y la mayoría han realizado por lo menos una campaña de seguimiento.

\section{Resumen del impacto}

En varios países ya se ha interrumpido la transmisión. En Cuba, después de la campaña de puesta al día con la vacunación realizada en 1987 y una campaña de seguimiento realizada en 1991, entre 1989 y 1992 se notificaron menos de 20 casos confirmados de sarampión por año. El último caso, confirmado serológicamente, se produjo en junio de $1993^{9}$. 
Tabla 1

Países que han realizado campañas de puesta al día con la vacunación y de vacunación de seguimiento, 1987-1998

\begin{tabular}{|c|c|c|c|c|c|c|c|}
\hline \multirow[t]{2}{*}{ Región } & \multirow[t]{2}{*}{ País/Territorio } & \multicolumn{2}{|c|}{$\begin{array}{c}\text { Campaña I-I } \\
\text { (Puesta al día) }\end{array}$} & \multirow{2}{*}{$\begin{array}{c}\text { Promedio } \\
\text { de cobertu- } \\
\text { ra en pro- } \\
\text { gramas de } \\
\text { rutina } \\
1994-1996\end{array}$} & \multicolumn{2}{|c|}{$\begin{array}{l}\text { Campañas } 1-4 \\
\text { (Campaña de } \\
\text { Seguimiento) }\end{array}$} & \multirow{2}{*}{$\begin{array}{c}\text { Año de la } \\
\text { próxima } \\
\text { Campaña } \\
\text { de Segui- } \\
\text { miento }\end{array}$} \\
\hline & & $A \tilde{n} o$ & $\begin{array}{c}\text { Cobetura } \\
(\%)\end{array}$ & & $A \tilde{n} o$ & $\begin{array}{c}\text { Cobetura } \\
(\%)\end{array}$ & \\
\hline \multirow[t]{5}{*}{ Andina } & Bolivia & 1994 & 98 & 90 & $\ldots$ & $\ldots$ & 1998 \\
\hline & Colombia & 1993 & 96 & 93 & 1995 & 90 & 1999 \\
\hline & Ecuador & 1994 & 100 & 70 & $\ldots$ & $\ldots$ & 1998 \\
\hline & Pcrú & 1992 & 75 & 87 & 1995 & 97 & 1999 \\
\hline & Venezuela & 1994 & 100 & 75 & 1998 & $\ldots$ & 1998 \\
\hline Brasil & Brasil & 1992 & 96 & 80 & 1995 & 77 & 1999 \\
\hline \multirow[t]{7}{*}{ Centroamérica } & Belice & 1993 & 82 & 82 & 1995 & 85 & 1999 \\
\hline & Costa Rica & 1993 & 75 & 90 & 1997 & $\ldots$ & $\ldots$ \\
\hline & El Salvador & 1993 & 96 & 89 & 1996 & 82 & 2000 \\
\hline & Guatemala & 1993 & 85 & 73 & 1996 & 60 & 2000 \\
\hline & Honduras & 1993 & 96 & 91 & 1996 & 85 & 2000 \\
\hline & Nicaragua & 1993 & 94 & 81 & 1996 & 97 & 2000 \\
\hline & Panamá & 1993 & 88 & 86 & 1996 & 94 & 2000 \\
\hline \multirow{17}{*}{$\begin{array}{l}\text { Caribe Inglés } \\
\text { y Suriname }\end{array}$} & Anguilla & 1991 & 99 & 97 & 1996 & 100 & 2000 \\
\hline & Antigua y Barbuda & 1991 & 96 & 95 & 1996 & 92 & 2000 \\
\hline & Bahamas & 1991 & 87 & 91 & 1997 & 78 & 2001 \\
\hline & Barbados & 1991 & 96 & 98 & 1996 & 91 & 2000 \\
\hline & Islas Caimán & 1991 & 85 & 92 & - & - & - \\
\hline & Islas Virgenes Británicas & 1991 & 88 & 100 & 1996 & 90 & 2000 \\
\hline & Dominica & 1991 & 95 & 95 & 1996 & 100 & 2000 \\
\hline & Granada & 1991 & 98 & 89 & 1996 & 81 & 2000 \\
\hline & Guyana & 1991 & 94 & 84 & 1996 & 90 & 2000 \\
\hline & Jamaica & 1991 & 71 & 87 & $1995 / 6$ & 85 & 1999 \\
\hline & Montserrat & 1991 & 100 & 100 & 1996 & 100 & 2000 \\
\hline & S. Cristóbal y Nieves & 1991 & 98 & 100 & 1996 & 100 & 2000 \\
\hline & S. Lucía & 1991 & 97 & 94 & 1996 & 85 & 2000 \\
\hline & S. Vicente y Granadinas & 1991 & 97 & 100 & 1995 & 84 & 1999 \\
\hline & Suriname & 1991 & 89 & 75 & 1997 & $\ldots$ & \\
\hline & Trinidad y Tobago & 1991 & 90 & 88 & 1997 & 96 & 2001 \\
\hline & Turkas y Caicos & 1991 & 81 & 98 & 1996 & 95 & 2000 \\
\hline \multirow[t]{3}{*}{ Caribe Latino } & Cuba & 1987 & 98 & 100 & 1993 & 99 & 1998 * \\
\hline & República Dominicana & 1993 & 77 & 84 & $\ldots$ & $\ldots$ & $1998 *$ \\
\hline & Haiti & 1994 & 94 & 28 & $\ldots$ & $\ldots$ & 1998 \\
\hline México & México & 1993 & 88 & 91 & 1998 & $\ldots$ & $\ldots$ \\
\hline \multirow[t]{4}{*}{ Cono Sur } & Argentina & 1993 & 97 & 98 & 1998 & $\ldots$ & $\ldots$ \\
\hline & Chile & 1992 & 99 & 94 & 1996 & 100 & 2000 \\
\hline & Paraguay & 1995 & 70 & 78 & $\ldots$ & $\ldots$ & 1998 \\
\hline & Uruguay & 1994 & 95 & 88 & $\ldots$ & $\ldots$ & 1998 \\
\hline
\end{tabular}

... Sin datos.

- No hubo campaña.

* Pendiente.

Datos al 21 de enero de 1998. 
Otros países de las Américas en los que parece haberse interrumpido la transmisión, son los países anglohablantes del Caribe, que realizaron la campaña de puesta al día con la vacunación contra el sarampión en mayo de 1991. Entre septiembre de 1991 y marzo de 1997 se notificaron sólo dos casos confirmados en los países anglohablantes del Caribe, ambos en Barbados (uno contrajo la infección en Nueva York y en el otro caso no se encontró la fuente), sin que se produjera una propagación secundaria ${ }^{10}$.

En Chile, tras la campaña de puesta al día, que se realizó en 1992, se descubrió un solo caso en 1992 (importado de Perú) y uno en 1993 (importado de Venezuela). No hubo propagación hasta 1997, año en el que se produjo un brote originado en un caso importado de Brasil, pero la transmisión de este brote ya se ha interrumpido.

La cifra registrada en las Américas en 1996 fue la más baja hasta el momento: solamente 2.109 casos confirmados de sarampión (figura 1). Sin embargo, en 1997 hubo un resurgimiento de la enfermedad en Brasil. A 31 de enero de 1998, los países de las Américas habían confirmado 53.661 casos de sarampión. Del total de casos confirmados, 52.284 fueron notificados por Brasil, los cuales, junto con los 579 casos confirmados de Canadá, representaron el 98,5\% del total de casos confirmados en la Región. No obstante, cabe señalar que en Canadá no se produjeron casos indígenas a partir de julio de 1997. Otros países que notificaron casos de sarampión en 1997 son Guadalupe (116), Estados Unidos (138), Paraguay (121), Argentina (125), Chile (58) y Costa Rica (26). Los brotes de Argentina, Chile, Costa Rica, Chile y Paraguay se originaron en casos importados de Brasil, y el de Guadalupe, de un caso importado de Francia a fines de $1996^{11}$. En esta isla no se habia aplicado la estrategia recomendada por la OPS para erradicar el sarampión. En Estados Unidos, más de la mitad de los casos se originaron en importaciones de Europa y Asia. La propagación a partir de casos importados fue limitada y el brote más grande de 1997 consistió en ocho casos solamente. En 1995

Figura 1

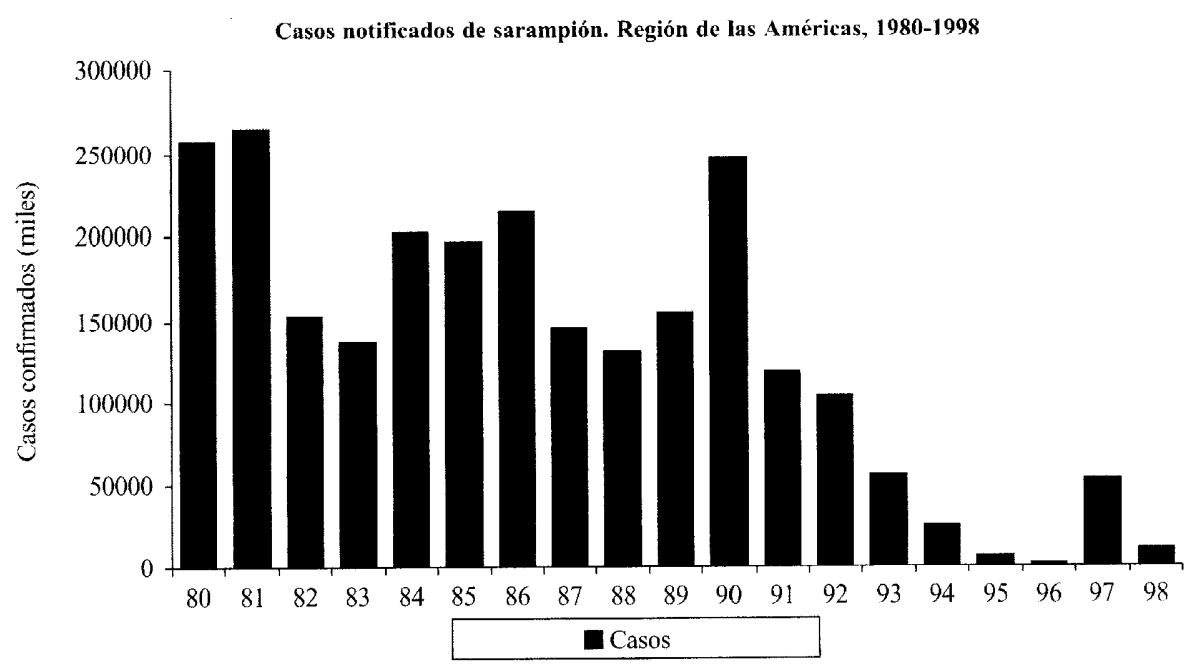

OPS 
y 1996 no se importaron casos de sarampión de América Latina o el Caribe. Sin embargo, en 1997 hubo cinco casos confirmados importados de Brasil ${ }^{12}$ (figura 2).

La mayoría de los casos de Brasil fueron notificados por el estado de São Paulo, el único que no hizo una campaña de vacunación de seguimiento en $1995^{13}$. Se han confirmado más de 48.000 casos de este brote, que en su mayoría se produjeron en la ciudad de São Paulo. Más del 50\% de los casos correspondieron a adultos jóvenes de 20 a 29 años. Los grupos con las tasas de incidencia más altas son los lactantes, los adultos jóvenes de 20 a 29 años y los niños de 1 a 4 años. Hasta la fecha se han notificado más de 25 muertes por sarampión, en su mayoría lactantes de menos de 1 año.

En una investigación de los casos de sarampión en adultos se observó que la mayoría estaba produciéndose en adultos jóvenes de ciertos grupos en riesgo, entre ellos hombres que habian migrado poco antes a la ciudad desde zonas rurales del nordeste para trabajar en obras de construcción y otros trabajos manuales, estudiantes, personal de salud, empleados del sector del turismo y reclutas de las fuerzas armadas ${ }^{14}$.

Se aisló virus del sarampión de varios pacientes de este brote y se determinó la secuencia del genoma, comprobándose que el virus que está circulando en São Paulo es prácticamente idéntico al virus que está circulando en Europa occidental, lo cual es un fuerte indicio de que el brote se originó en casos importados de Europa ${ }^{15}$.

El brote de São Paulo fue controlado tras una respuesta enérgica que incluyó una campaña de vacunación de seguimiento dirigida a todos los niños de 1 a 4 años, la vacunación selectiva de barrido en escuelas y la vacunación de adultos jóvenes de grupos que corren un alto riesgo de contracr sarampión ${ }^{14}$.

Hasta 1997, en los países anglohablantes del Caribe, no se había notificado ningún caso confirmado de sarampión en más de cinco años ${ }^{16}$. Sin embargo, en 1997 se confirmaron dos casos en laboratorio. El primero fue notificado por las Bahamas. El paciente, un adulto joven, presentó exantema en marzo de 1997. No se logró identificar la fuente directa de transmisión, pero se sospecha firmemente que el paciente se contagió de un turista. Se hizo una búsqueda en el país para detectar cualquier otro caso de sarampión que pudiera haberse producido. Como parte de esa búsqueda se examinaron más de 80.000 diagnósticos de centros de salud del país ${ }^{17}$. El segundo caso fue notificado por Trinidad y Tabago. Fue un adulto joven: un marinero italiano que presentó exantema en abril. Fl paciente había contraído el sarampión en Italia. Se obtuvo una muestra y en el laboratorio para sarampión del Centro de Epidemiología del Caribe (CAREC) se determinó que contenía IgM contra el sarampión. A pesar de que se realizó un estudio cuidadoso, no se detectó una propagación.

Durante 1998, hasta el 21 de diciembre, los países de las Américas habían notificado un total de 26.103 casos sospechosos de sarampión, de los cuales 9.628 (37\%) fueron descartados tras un estudio epidemiológico y de laboratorio completo, 9.598 (37\%) fueron confirmados como sarampión y 6.877 $(26 \%)$ continúan en estudio.

Aunque los datos para 1998 todavía no están completos, se observa una disminución del $82 \%$ en los casos de sarampión en comparación con el total de 53.661 casos confirmados notificados en 1997. En ese año, del total de casos confirmados, 9.005 (94\%) fueron confirmados en el laboratorio o presentaban una conexión epidemiológica con un caso confirmado en laboratorio, y $590(6 \%)$ fueron confirmados clínicamente.

Argentina ( 7.054 casos confirmados) y Brasil (2.006 casos confirmados), considerados conjuntamente, representan el $94 \%$ del total de casos confirmados de sarampión en las Américas durante 1998 (figura 2). 
Otros países, en los que se documentó una importante circulación del virus, fueron Bolivia (351 casos confirmados), Estados Unidos (86) y Paraguay (68). Los demás países de la Región, en conjunto, notificaron un total de 33 casos confirmados, varios de los cuales fueron importados de otros países y los demás fueron aislados desde el punto de vista tanto del momento como del lugar en el que se produjeron.

Figura 2

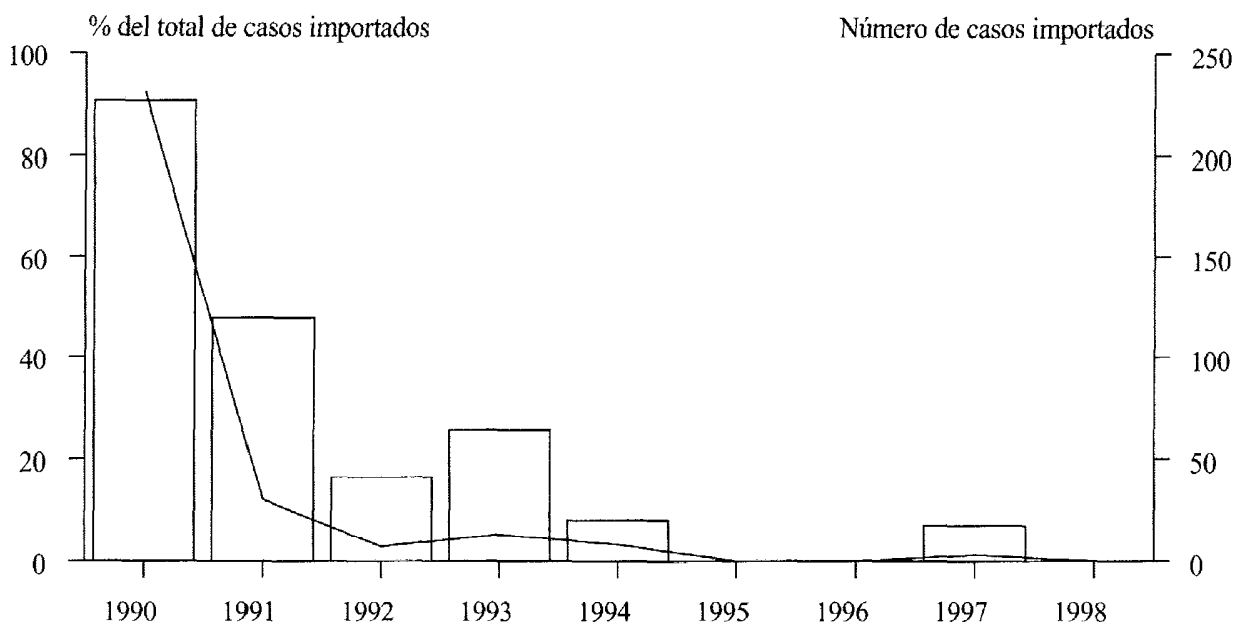

Año

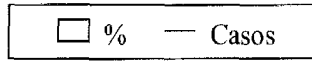

En 1998, el brote más grande de la Región fue el de Argentina. Del total de casos notificados allí, $6.026(85 \%)$ lo fueron en la zona metropolitana de Buenos Aires. Del total de casos de éstos, 4.239 (60\%) se produjeron en lactantes y menores de 5 años que, en su mayoría, no estaban vacunados. Otras provincias de Argentina que notificaron una gran cantidad de casos fueron Tucumán (212), Misiones (177), Chaco (97) y Jujuy (93). A 21 de diciembre se habían notificado 56 muertes relacionadas con el sarampión, principalmente de lactantes y preescolares que no estaban vacunados.

En Brasil, durante 1998, el virus del sarampión circuló principalmente en el sur y el sud- este, aunque se notificaron casos en todas las regiones. Los estados que notificaron una gran cantidad de casos confirmados fueron Paraná (804), São Paulo (403), Amazonas (258), Pernambuco (166) y el Distrito Federal (144). A diferencia de Argentina, donde la mayoría de los casos se produjeron en lactantes y preescolares sin vacunar, la mayoría de los casos en Brasil correspondieron a adultos jóvenes que no estaban vacunados.

\section{CONCLUSIONES}

Aunque el resurgimiento del sarampión en las Américas durante 1997 representa un aumento importante en comparación con los 
casos notificados en 1996, el total representa, solamente, alrededor del $10 \%$ de los casos notificados en 1990. No obstante, se pueden extraer enseñanzas importantes de esta experiencia.

Primero, la falta de una campaña oportuna de vacunación de seguimiento en São Paulo en 1995, para los niños de 1 a 4 años, combinada con la baja cobertura de la vacunación de rutina (vacunación de mantenimiento) de los lactantes con dos dosis, permitió la acumulación rápida y peligrosa de niños susceptibles. Segundo, la presencia de una gran cantidad de adultos jóvenes que no estuvieron expuestos a la infección natural, pero que tampoco fueron vacunados, exacerbó el riesgo de un brote. Tercero, el virus del sarampión fue importado a São Paulo, probablemente, desde Europa. Por último, la gran densidad de población de la ciudad facilitó el contacto entre las personas infectadas y las susceptibles.
Los datos de la vigilancia del sarampión, combinados con los resultados de estudios epidemiológicos moleculares, indican que los países de las Américas están expuestos constantemente a virus de otras regiones del mundo, en las que el sarampión sigue siendo endémico. En 1997 se detectaron 23 importaciones de virus del sarampión de Europa, 17 de Asia y 2 de África (figura 3) que desencadenaron la transmisión. Sin embargo, estos datos, probablemente, subestimen mucho la verdadera cantidad de importaciones de sarampión, ya que muchos casos importados tal vez no reciban atención médica ni desencadenen la transmisión.

Asimismo, los brotes de Brasil, Canadá y otros países de la Región, indican que podría haber una gran cantidad de adultos jóvenes que siguen siendo susceptibles a la enfermedad. Por razones prácticas, se puede suponer que las personas nacidas antes de 1960, en la mayoría de los países de las Américas, han

Figura 3

Importaciones de sarampión en la Región de las Américas, 1997

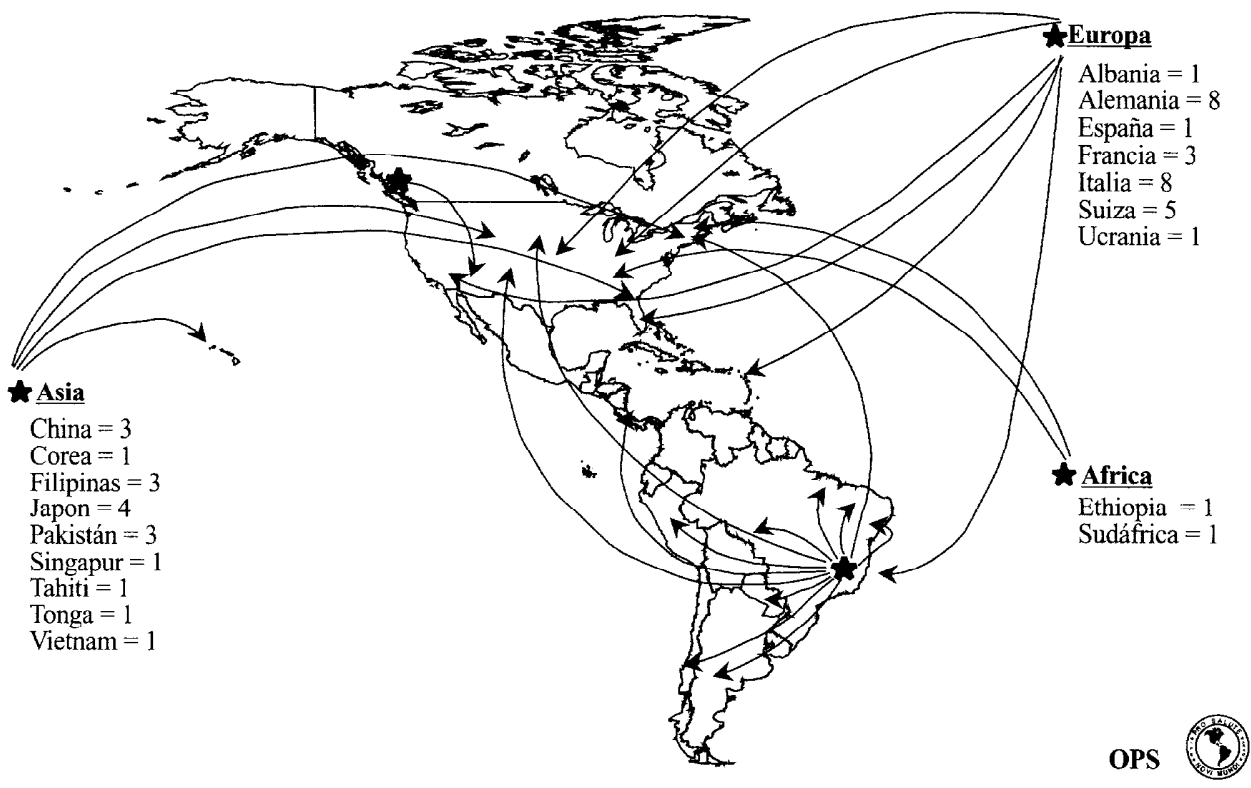


estado expuestas al virus del sarampión en circulación y que, por lo tanto, están inmunizadas contra la enfermedad. En consecuencia, la gran mayoría de los adultos ya son inmunes, y la mayoría de los adultos jóvenes susceptibles corren un riesgo muy bajo de exposición al virus del sarampión.

No se recomienda realizar campañas de vacunación masiva de adultos jóvenes. Sin embargo, se sabe, por experiencia, que en ciertos medios institucionales, como universidades, cuarteles militares, centros de salud, grandes fábricas y cárceles, el sarampión puede transmitirse fácilmente si el virus se introduce en estos grupos. Además de las personas que viven o trabajan en estos medios, los adolescentes y los adultos jóvenes que viajan a países en los que la transmisión del sarampión es endémica corren mayor riesgo de exposición y de contraer sarampión. A fin de evitar los brotes entre adolescentes y adultos jóvenes en estos medios, hay que tomar medidas para garantizar la inmunidad de los grupos que corran un alto riesgo y de las personas que viajen a países donde el sarampión es endémico.

La experiencia de 1997 con el sarampión muestra claramente dos desafíos importantes que son necesarios superar, a fin de erradicar el sarampión de la Región para el año 2000. Primero, los países de las Américas deben mantener el mayor grado de inmunidad posible de los lactantes y niños, y vacunar a los adolescentes y adultos jóvenes que corren el mayor riesgo de exposición al virus del sarampión. Segundo, es necesario intensificar las medidas en otras regiones del mundo para mejorar el control del sarampión y disminuir la exportación de casos a las Américas. Mientras que el virus del sarampión siga circulando en el resto del mundo, la región de las Américas seguirá corriendo el riesgo del sarampión. Para alcanzar la meta de la erradicación del sarampión es necesario aplicar plenamente la estrategia de vacunación recomendada por la OPS en todos los países de la Región y mejorar el control y la eliminación del sarampión en las demás regiones del mundo, especialmente Europa y Asia, con la meta final de erradicar el sarampión de todo el mundo ${ }^{18}$.

\section{BIBLIOGRAFÍA}

1. Pan American Health Organization. Measles Elimination by the Year 2000. EPI Newsletter 1994: 16: $1-2$.

2. Krugman S, Katz SL, Gershon AA, Wilfert C. Infectious diseases of children. 8th Edition. St. Louis: The C.V. Mosby Company; 1985.

3. Krugman S, Giles JP, Jacobs AM, Friedman H. Studies with a further attenuated live measles-virus vaccine. Pediatrics 1963; 31: 919-28.

4. Markowitz LE, Preblud SR, Fine PEM, et al. Duration of measles vaccine-induced immunity. Ped Infect Dis J 1990; 9: 101-110.

5. Fine PEM, Clarkson JA. Measles in England and Wales. En: An analysis of factors underlying seasonal patterns. Int J Epidemiol 1982; 11: 5-14.

6. Mclean AR, Anderson RM. Measles in developing countries Part I. Epidemiological parameters and patterns. Epid Infect 1988; 100: 111-133.

7. Clements CG, Strassburg M, Cutts FT, et al. The Epidemiology of Measles. World Health Stat Quart 45: 285-291, 1992.

8. de Quadros, CA, Hersh, BS, Olive, JM et al. Measles Elimination in the Americas: Evolving Strategies. JAMA. 275: 224-229.

9. Pan American Health Organization. Expanded Program on Immunization. Progress Report to the PAHO Executive Committee. Document CE113/11. Washington, D.C. 26 de abril de 1994.

10. Hospedales CJ. Update on elimination of measles in the Caribbean. W I Med J 1992; 41: 43-44.

11. Pan American Health Organization. Measles in the Americas, 1997. EPI Newsletter 1997. 19: 6: 1-3.

12. Pan American Health Organization. Measles in the Americas, 1997. EPI Newsletter 1997. 19: 6: 1-3.

13. Pan American Health Organization. Update: Sao Paulo Measles Outbreak. EPI Newsletter 1997. 19: 6: 1-3.

14. Pan American Health Organization. Measles in the Americas, 1997. EPI Newsletter 1997. 19: 6: $1-3$.

15. Pan American Health Organization. EPI Newsletter 1996. 18: 6: 1-3. Irons, B, Carrasco, PA. Joint $\mathrm{CDC} / \mathrm{PAHO} / \mathrm{WHO}$ measles meeting report. 